\title{
MONITORING OF FLANK WEAR AND DAMAGE ON TURNING CUTTING TOOLS BY IMAGE PROCESSING
}

\section{MONITORAMENTO DO DESGASTE DE FLANCO E AVARIAS EM FERRAMENTA DE CORTE DE USINAGEM POR PROCESSAMENTO DE IMAGENS}

\section{J. K. KHOURY JUNIOR ${ }^{1 *}$, J. K. SCHUELLER ${ }^{2}$, F. A. C. PINTO ${ }^{3}$ and G. P. VILLIBOR ${ }^{1}$}

${ }^{1}$ Universidade Federal de Viçosa, Departamento de Engenharia de Produção e Mecânica, Viçosa, MG, Brazil

${ }^{2}$ University of Florida, Mechanical and Aerospace Engineering, Gainesville, FL, USA

${ }^{3}$ Universidade Federal de Viçosa, Departamento de Engenharia Agrícola, Viçosa, MG, Brazil

"Joseph Kalil Khoury Junior. Universidade Federal de Viçosa, Departamento de Engenharia de Produção e Mecânica, Viçosa, MG, Brazil, Phone:+55 31. 988851815

e-mail address:kalil@ufv.br (J.K. KhouryJunior).

\begin{tabular}{l} 
A R T I C L E I N F O \\
\hline Article history: \\
Received 2019-12-03 \\
Accepted 2020-06-17 \\
Available online 2020-06-17 \\
pa lavras-chave \\
Fabricação de máquinas \\
Usinagem \\
Visão artificial \\
Controle de qualidade \\
keywords \\
Manufacturing \\
Machining \\
Vision machine \\
Quality control \\
\end{tabular}

\begin{abstract}
A B S T R A C T
The development of the tool wear monitoring system by machining processes has been well recognized in the machine industry mainly due to the growing demand for product quality and improved productivity. For this, artificial vision systems have been used as a measurement tool in various application areas. Thus, the objective was to develop a system automatic based in the image processing to identify and measure flank wear in machining tool. Image processing techniques, discriminant function, to identify insert breakage, and Hough Transform, to find the flank wear profile, achieved over accuracy. Consequently, 94.3\% to identify between worn and broken insert and $0.04 \mathrm{~mm}$ mistake in measurement of flank wear width compared with microscope.
\end{abstract}

R E S U M O

O desenvolvimento de sistema de monitoramento de desgaste de ferramentas por processos de usinagem tem sido bem reconhecido no setor de máquinas pricipalmente pela crescente demanda por qualidade do produto e melhoria da produtividade. Para isso, sistemas de visão artificial tem sido usado como ferramenta de medição em várias áreas de aplicação. Assim, o objetivo foi desenvolver um sistema automático baseado no processamento de imagens para identificar e medir desgaste de flanco em ferramenta de usinagem. As técnicas de processamento de imagem, função discriminante, para identificar quebra de pastilha, $e$ Hough Transform, para encontrar o perfil de desgaste do flanco, alcançaram execelente precisão. Consequentemente, 94,3\% para identificar entre inserto com desgaste ou quebrado e 0,04 mm de erro na medida da largura do desgaste do flanco comparado medido no microscópio. 


\section{INTRODUCTION}

A criterion widely used to replace cutting tools is the measurement of the maximum flank wear. However, this measurement is time consuming. The current automated processes available are limited to large companies, due to high capital demanded. The development of tool wear monitoring system for machining processes has been well recognized in industry due to the ever-increased demand for product quality and productivity improvement. Due to the increasing speed and reduction in price of the computers, the vision machine system has been larger used as measure tools in several application areas. Thus, many researchers have studied better techniques for these purposes and above all techniques of image processing, like shown in this study.

The tool wear predictive for a combination of the nonlinear model and principal component technique to extract features from multiple sensory signals like force, vibration and acoustic emission acquired from machining processes. Then, the tool wear prediction model is constructed by learning correlation between extracted features and actual tool wear. The effectiveness of proposed predictive model and corresponding tool wear monitoring system is demonstrated by experimental results from broaching trials and a good agreement can be found between predicted tool wear constructed by model and actual tool wear measured by optical scan microscope (Kang et al., 2019, Shi et al. 2007).

Several authors have been investigated methods to estimate tool wear on coated insert. Capasso (2019) based on experimental data obtained from several tests under different cutting conditions and flank wear prediction equation was reliability with an R-value Óldif 93\%. Liew et al. (2007) investigated the wear of coated carbide and uncoated carbide tools during milling of a stainless steel at low speeds (25 and 50 $\mathrm{m} / \mathrm{min}$ ) in workpiece from 35 to 55 HRD hardness. It was found that increasing the hardness of the workpiece from 35 to 55HRC caused an increase in the flank wear and the coated tool, which exhibited higher wear resistance than the uncoated tool, produced better surface finish. The rake and flank wear $(\mathrm{Vb})$ were used by Xiong et al. (2013) to availed tool life during dry cutting for AISI H13 hardened steel using ultrafine cemented carbides. Tool life was analyzed by an extended Taylorôs tool life equation, indicating that cutting speed played a profound effect on the tool life and wear behavior of both cutting inserts.

Zhang et al. (2013) developed a new online tool wear measuring algorithm is proposed to acquire tool wear using machine vision to establish on-line tool wear monitoring model for assessing degree of wear and remaining useful tool life. The machine vision to acquire tool wear images from CCD camera on-line for ball-end cutter. The similar as the Sobel edge operator was used for detection of wear edge. The obtained measurement results by using the proposed method are compared with those gotten by measuring directly with microscope. The proposed method is shown to be reliable and effective for on-line tool wear measurement.
Bhushan 2013 used tool wear in turning operation as a set of the machining parameters to satisfy the objectives of the minimum flank and crater wear, the maximum metal removal rate. The main machining parameters which are considered as variables of the optimization are the cutting speed, feed rate, depth of cut, and nose radius. The optimum set of these four input parameters is determined for a job-tool combination of $\mathrm{Al}$ alloy and tungsten carbide insert CNMG 120404, 06 and 08, which minimizes the tool wear and maximizes the metal removal rate. The regression models developed for the minimum tool wear and the maximum metal removal were used for finding the multi response optimization solutions. A method for simultaneous optimization of the multiple responses based on an overall desirability function was used. The multi-objective optimization resulted in a cutting speed of $210 \mathrm{~m} / \mathrm{min}$, a feed of $0.16 \mathrm{~mm} / \mathrm{rev}$, a depth of cut of $0.42 \mathrm{~mm}$, and a nose radius of $0.40 \mathrm{~mm}$. These machining conditions are expected to respond with the minimum tool wear and maximum metal removal.

Thus, the aim is to develop an automatic system based on image processing to identify and measure tool wear.

\section{MATERIAL E METHODS}

\section{Machine Vision Prototype}

It was acquired 244 sampled images of the minor flanks face of CNMG 160616 RP ISO (Kennametal) carbide tools previously used in industry in turning machine with flank wear and breakage. The image acquisition system consisted of a mechanical system for a flexible measurement of the flank, four axes were required for positioning the camera for tools on turning. Two axes were used to positioning the camera base to front turning and more two axes to driving arm camera mechanism to cutting tool head in focus (Fig.1). A Dino-lite microscope camera (Dino X Lite $̈$ I AM413 T-X) with led illumination, which obtained images with a dimension of 1600 x 1200 pixels, a resolution $7.5 \mathrm{\varepsilon m}$. This resolution was determined with base of the number pixels on the thickness insert $(6.5 \mathrm{~mm})$. In Figure 1 are shown the acquire system.

\section{Image Processing}

The software used for image processing was Matlab, and for statistical analysis was SAS. To achieve of goal of a measurement of flank wear, six steps of processing image were development after the color image was converted to grayscale image and an adjust intensity histogram is performed for decrease illumination variation environment. The adjust image intensity values from image to new values for such that $1 \%$ of data is saturated at low and high intensities of image. This increases the contrast of the output image. In order to the basic image processing are the following: (A) segmentation of the flank wear region (B) features extraction, (C) check type classification for breakage or flank wear, (D) edge detection flank wear, (E) find lines perpendicular using Hough transform, and finally $(\mathrm{F})$ flank wear measurement. Each of them consists a certain number of image processing steps with special configuration parameters. 

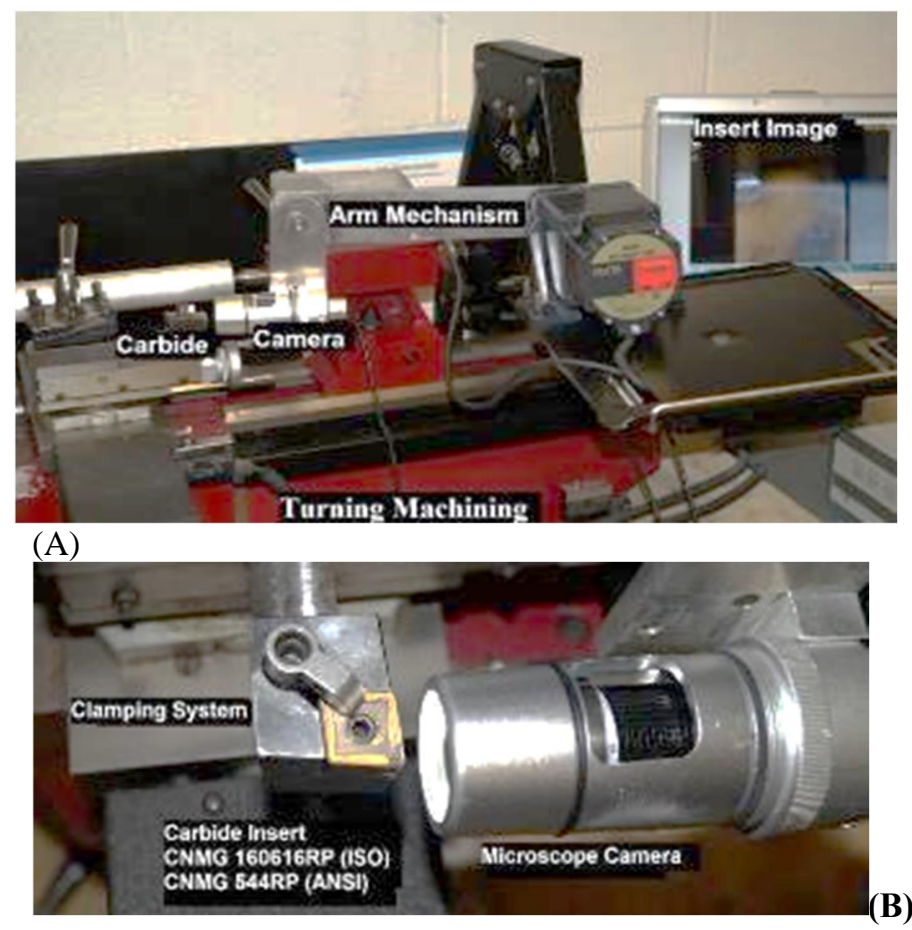

Figure 1 - System acquire tool insert images: (A)image acquisition system on turning and (B) detail microscope camera, clamping and carbide insert.

\section{A) Segmentation of the flank wear region}

In this step the tool area could be separated from image background by finding the top and side tool edges using technical to edge detection (Gonzalez and Wood, 2008; Matlab, 2009; Maini et al., 2009). To detect both edges were applying Canny edge and Sobel edge (Fig.2- B), dilate, fill hole and erode techniques (Fig 2 B-E). In order to the original insert borders are determined. After this can defined a cut image of goal wear region on the flank (Fig. $2 \mathrm{~F}$ ).

\section{B) Features extraction}

The features used were percentiles of gray level, and texture features from the matrix of co-occurrence from grey image and edge image.

The percentiles used were $2,5,10,20,30,40,50,60,70$, 80,90 and $95 \%$. The difference between 2 and $95 \%$ percentiles was used to normalize the features, thereby making them invariant to illumination, as described by Khoury Junior et al. (2005) Eq. (1):

$$
C^{y}=\frac{P^{y}}{P^{95 \%}-P^{2 \%}}
$$

where: = normalized percentile $\mathrm{y} ; \quad=$ percentile $\mathrm{y}$ of the gray levels image; $y=2,5,10,20,30,40,50,60,70,80,90$, $95 \%$.
Original Image (A)

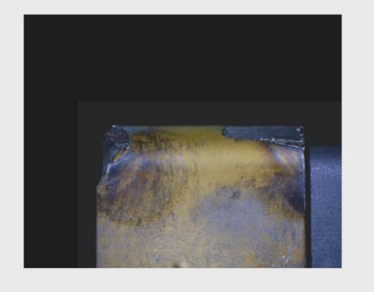

Dilate (C)
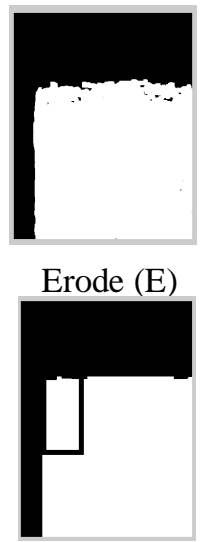

Edge Cany and Sobel (B)

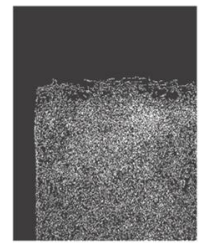

Fill hole (D)

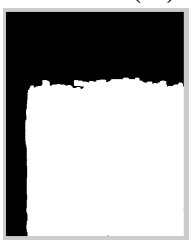

Region Goal (F)

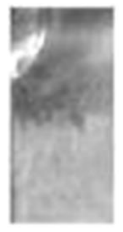

Figure 2 - Steps to segmentation of the flank wear region,

The texture features contrast, homogeneity and energy were determined from the co-occurrence matrix in three different directions, vertically, horizontally and diagonally, totaling nine texture features ( 3 features $\mathrm{x} 3$ directions) after rescale the 256 gray level images to eight gray levels. The same way as contrast, homogeneity and energy were determined from edge image ( 3 features $x 3$ directions) obtained by plus Canny and Sobel edge image. Thus, it was used a totally of the 30 features, 12 percentiles plus 18 texture features.

In order to select those variables with the greatest potential for discrimination, it was used the stepwise method. In this method, the discrimination power of a feature was assessed by the Wilks Lambda criterion, using a significance level to enter and stay in the model of 0.35 . The procedure 'STEPDISC' of the SAS program was used for this task (SAS, 2000).

\section{C) Check type classification for breakage or flank wear}

It was used a Bayesian classifier, where the parameters are the mean, covariance and priori probability of the classes (Johnson \& Wichern, 2007). The probability of classifying an individual in a class $\mathrm{j}, \mathrm{P}(\mathrm{wj} \mid \mathrm{X})$ or $\mathrm{Dj}(\mathrm{X})$, when considering different covariances for each class, is estimated by quadratic discriminant function Eq. (2):

$$
D_{j}(X)=-\frac{1}{2}\left(X-\bar{X}_{j}\right)^{T}\left(\breve{\mathbb{E}}_{j}\right)^{-1}\left(X-\bar{X}_{j}\right)-\frac{1}{2} \ln \left|\breve{E}_{j}\right|+\ln \left[P\left(w_{j}\right)\right]
$$

where: $\mathrm{Dj}(\mathrm{X})=$ discriminant function value for class $w_{j}$ of vector $X ; X=$ feature vector of on observation; $=$ the mean feature vector of class $\mathrm{j} ; \Sigma \quad$ covariance matrix estimation of class $\mathrm{j} ;|\Sigma|$ determinant of covariance matrix estimation $j$; e $P(w j)=$ a priori probability of class $\mathrm{j}$. 
It was considered a priori probabilities of proportional class sample. For $k$ classes defined previously in the image (breakage and flank wear), the feature vector X representing an observation is classified into the $j^{\text {th }}$ class if $D j$ is maxima between two class, Breakage and Flank wear insert (Figure 3) .

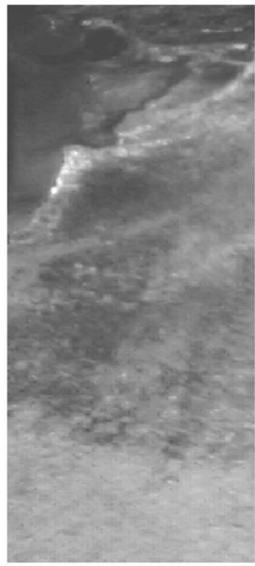

(A)

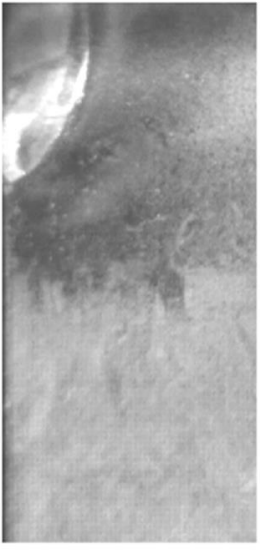

(B)

\section{Figure 3 - Classification an observation into two pattern} breakage (A) or flank wear(B)

\section{D) Edge detection flank wear}

These next steps are realized just in the insert without breakage so this type was removes in the step before. In the flank wear region predefined before (Fig. 2 F) are realized the following image processing: First all run the detection of Canny edge. Second, take off from image edge all connected pixels that have fewer size clusters, in this case was choose 120 pixels. Finally, create a edge of $0.2 \mathrm{~mm}$ on the top of insert, this procedure remove the need the analyze in a region that tool wear level is regularly used. According the ISO 3685 (1993); Tlusty (2000) and Zhang (2013) most commonly criteria to the maximum level of tool wear for carbide tools are the Flank Wear Width maximum FWW max. $=0.6 \mathrm{~mm}$ and Flank Wear Width average FWW avg. $=0.3 \mathrm{~mm}$, these values are larger than the program will analyzed, allowed inspection this FWW before the end life tool. Considering these processing images, the tool wear flank level will be analyzed starting from $0.2 \mathrm{~mm}$ of FWW.

\section{E) Find lines perpendicular using Hough transform}

For the Hough Transform (Gonzalez \& Wood, 2008; Mannan el al. 200; Matlab, 2009) a image pixel represented for point $(\mathrm{x}, \mathrm{y})$, cartesian coordinate, can be transformed in parametric radius (rho) and angle (theta), polar coordinate Fig. 5(A). The variable rho is the distance the vector from origin system to a point. Theta is the angle between this vector in degrees clockwise from the positive $\mathrm{x}$-axis. Thus, the representation each pixel found on image are transformed for rho $=x^{*} \cos ($ theta $)+y^{*} \sin ($ theta), Standard Hough Transform (SHT), for range of the theta $0^{\circ}$ to $90^{\circ}$ (Fig. 5 B). This SHT allowed find every pixels collinear and a specific direction. For example, in direction theta equal $45^{\circ}$ are $(3,5)$ and $(2,6)$ collinear, in $72^{\circ}$ are $(5,5)$ and $(2,6)$, and in $90^{\circ}$ are $(0,5),(3,5)$, and $(5,5)$.
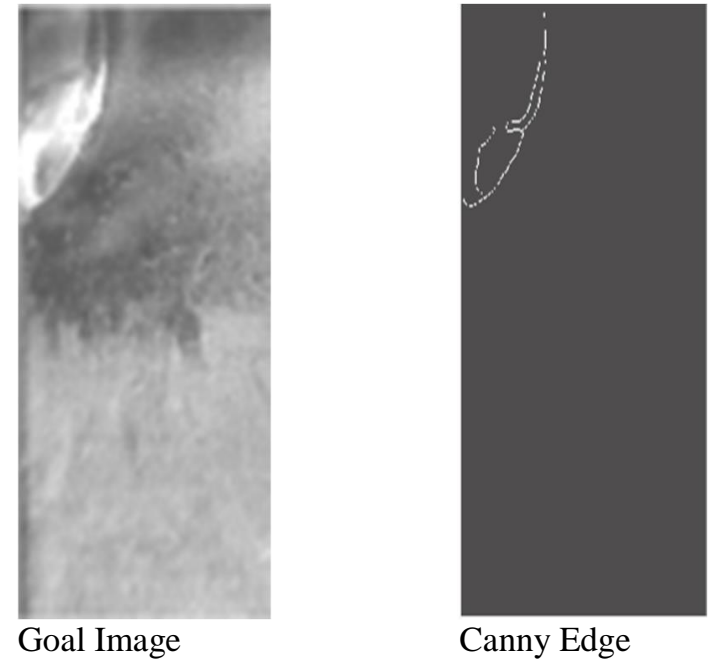

Canny Edge
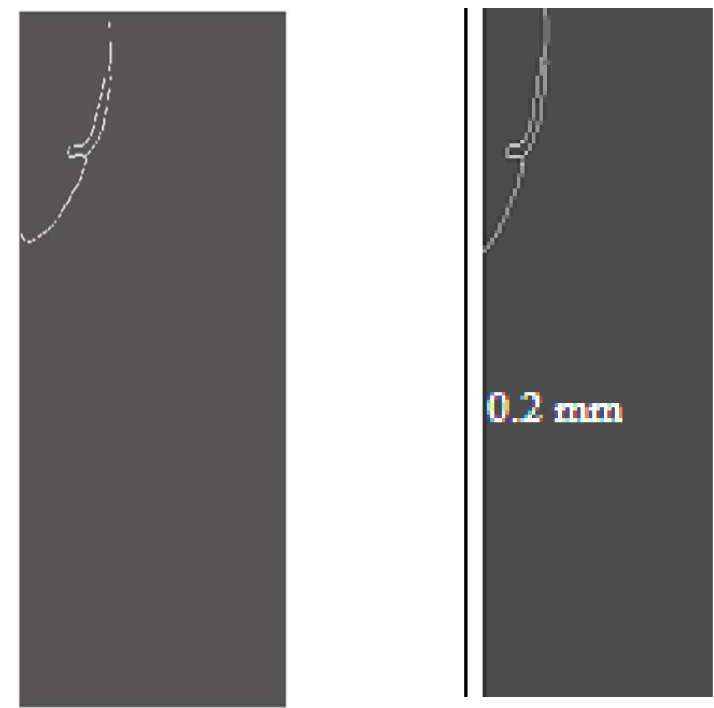

Remove connected pixels fewer

Create a edge of $0.2 \mathrm{~mm}$ on the top of insert

Figure 4 - Edge detection flank wear.

With SHT can find these points and direction through of the intersection the lines in graphic Fig.5 B. The lines that intersect each other in theta equal $90^{\circ}$ are corresponding those pixels collinear and perpendicular from axe Y. In this work, these points was perpendicular direction from top insert that will represent profile flank wear Fig. 5 (C) (D). The ñHoughò and ñHoughlinesò syntax was used in MatLab program. In addition, a routine for computer program can select on finding lines which the length longer than $0.2 \mathrm{~mm}$ (minimum FWW analyzed) and shorter than $1.1 \mathrm{~mm}$ (maximum FWW analyzed) that remove any lines segment that are without of the goal to measure.

After this can find all lines between pixels from edge image with specific direction and length. This last step become the program more robustness because just the found perpendicular lines are the range of the interest to measure FWW.

After lines on flank wear detected, the measurement of its parameters is performed. According the ISO 3685 (1993), Tlusty (2000) and FWW average FWWav (VB) and maximum FWWmax (VBmax) are calculated. The FWWav is the average the length perpendicular line found on flank wear and FWWmax is a bigger than its, Fig. $5(\mathrm{~F})$. 
In Fig 6. is flowchart algorithm and image processing to the tool wear and breakage inspection system.

(A)Four Points (x, y)

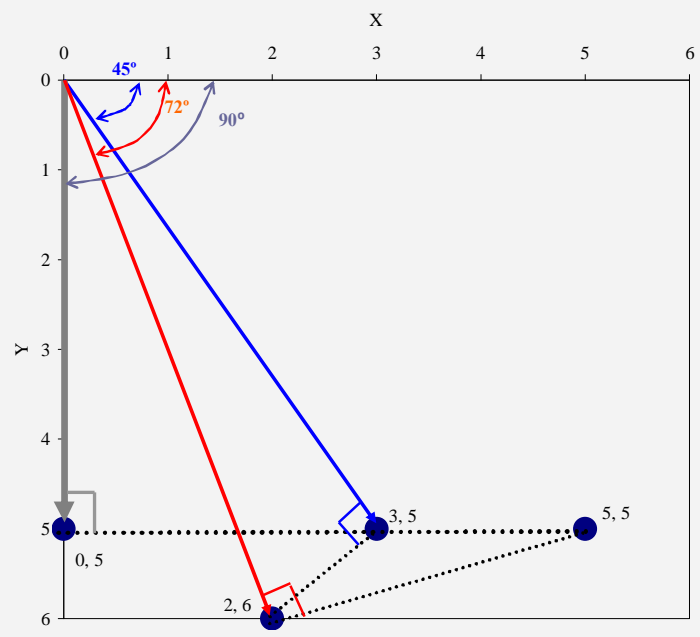

(C) Edge Image

with $\mathrm{n}$ white pixels

(E) Original image

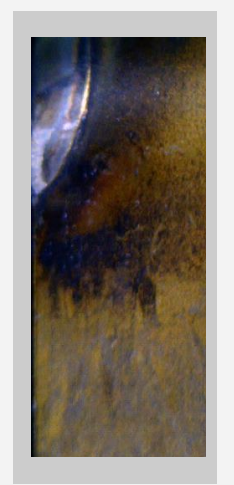

(B) Four Curves $r h o=x * \cos ($ theta $)+y * \sin ($ theta $)$,

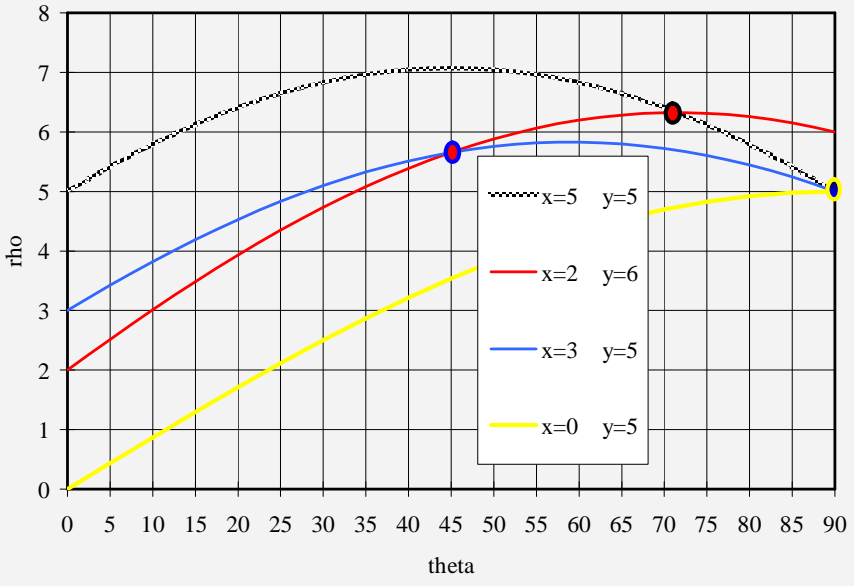

D) Hough transform from pixels edge image

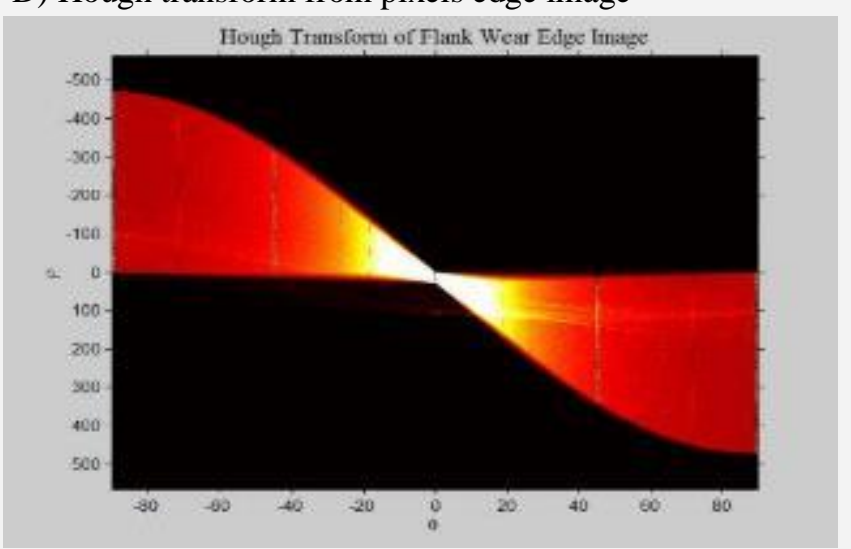

(F) Lines represented tool wear

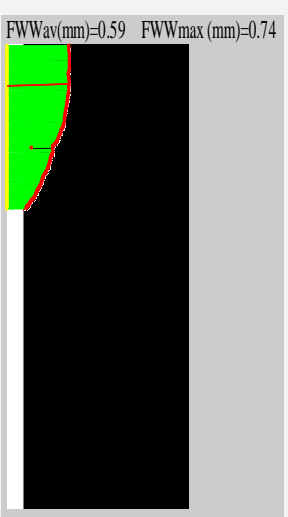

Figure 5 - Step for Hough transform (A) to (B) to find the collinear points of the perpendicular line from $Y$ axe (theta $=$ $\left.90^{\circ}\right)$, points $[(0,5),(3,5)$ and $(5,5)]$ in $(A)$ are collinear because it curve intercepted each other in theta $90^{\circ}(B)$. Hough transform (C) to (D) to find the collinear pixels and perpendicular from top of the insert. White pixels in (C) are representing FWW edge and original contour insert. The curves intercepted each other in theta \pm 90 are the pixels collinear and perpendicular from top insert. Original image (E) and lines segments perpendicular (F) from top insert, and lines selected between $0.2 \mathrm{~mm}$ and $1.1 \mathrm{~mm}$. 


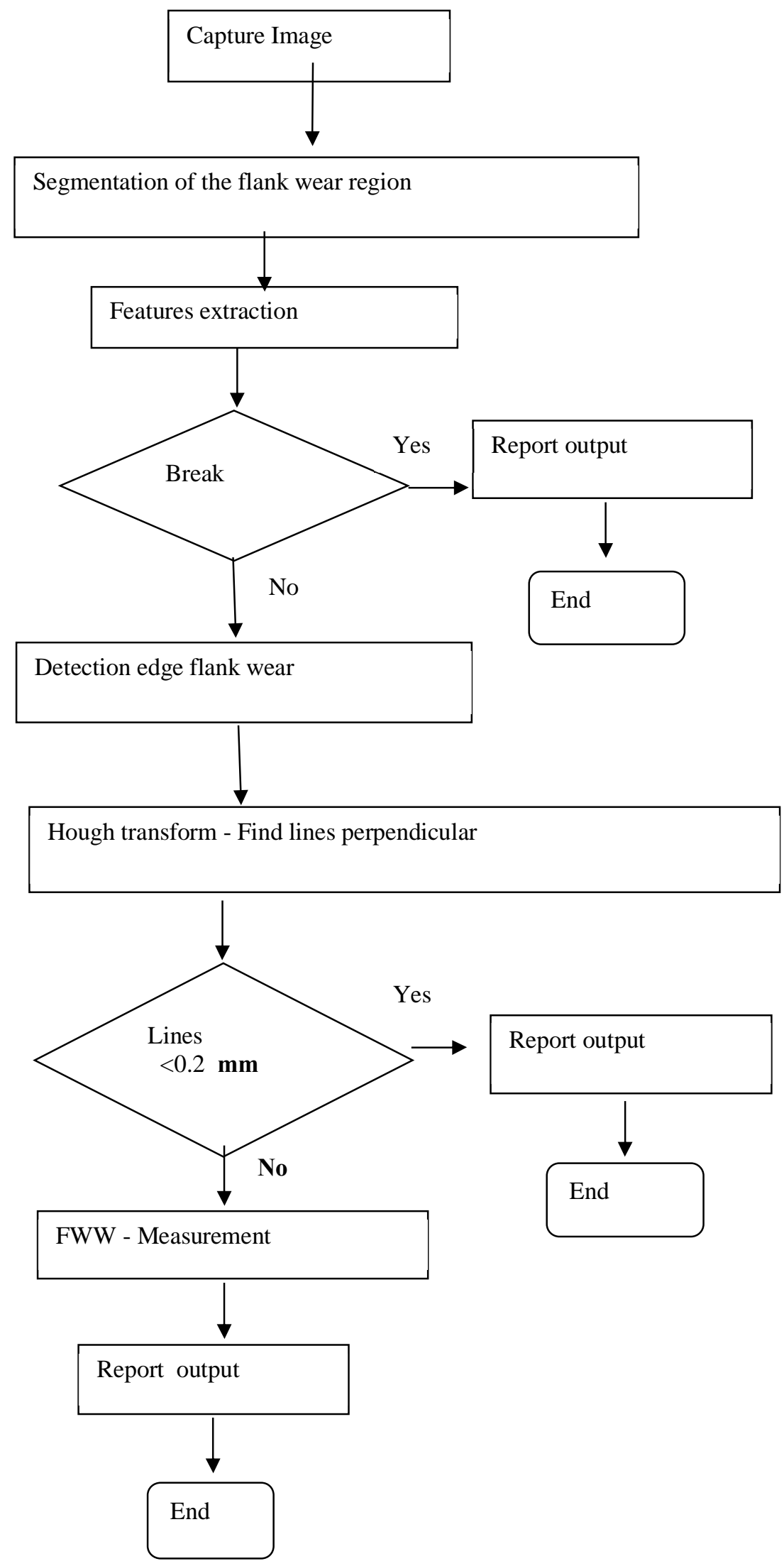

Figure 6 - Flowchart algorithm and image processing to the tool wear and breakage inspection system

The classification errors from discriminant function were accessed by leave-one-out crossvalidate using ñdiscrim procedureò by SAS program (SAS, 2009). Using the classification errors was built a graphic for analyzed the discriminant power by types features image. The result tool wear, FWWavg and FWWmax, by program developed were 
compared with 10 images insert acquired by microscope optic (Nikon ShuttlePIx P-400R) and Surface Profilometer (Zygo New View 7200).

\section{RESULT AND DISCUSSION}

The 12 features were selected by the stepwise method from 30 features. Which 6 percentiles features, three texture features from gray image and three texture features from edge image. This result showed that both kinds of features were important to discriminate the studied patterns. However, when used both features obtained $94.3 \%$ accurate (Fig. 7).

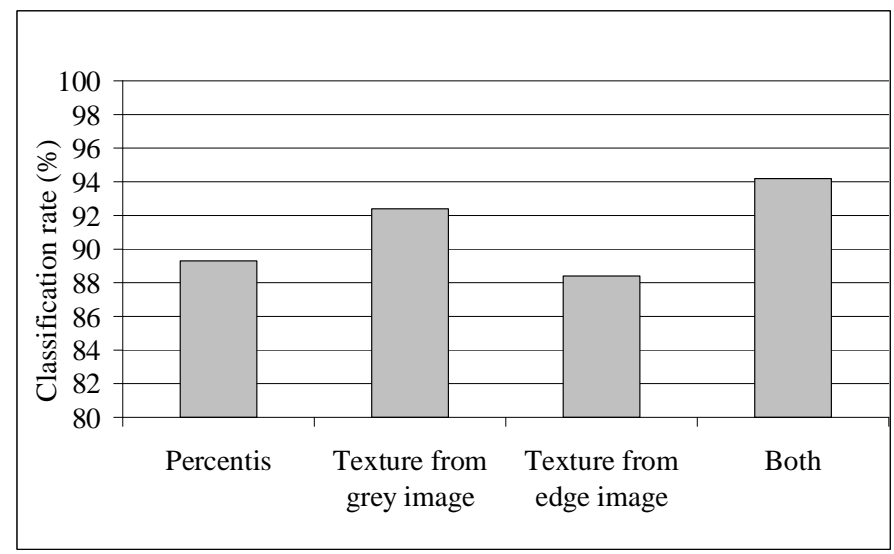

Figure 7 - Classification tool wear and breakage.

In the Fig. 8 is an sample of the result of steps on the image processing, following: (A) original image, (B) contour of insert, (C) goal image, (D) edge image, (E) removal noises and add bar of $0.2 \mathrm{~mm}$ in top insert, $(\mathrm{F})$ lines found using Hough transform and the FWW (flank wear width) average of $0.21 \mathrm{~mm}$ and maximum of $0.23 \mathrm{~mm}$. This interface is presentation for user of the program, where start with image original and finished with the measure of the flank wear insert.

In the Fig. 9 shown the deviation of the FWW max by developed machine vision system between optical microscope and surface profile. The deviation between optical microscope and Vision System was average of the $0.04 \mathrm{~mm}$, and surface profile was of the $0.08 \mathrm{~mm}$. These deviation values are acceptable considering that the usually the FWW monitoring for machining are for accuracy of $0.1 \mathrm{~mm}$ (ISO 3685, 1993) and in both validations showed to be below it. The mistake or accuracy found similarly and acceptable for others authors, Kang et al.
(2019) found accuracy about $92 \%$ to $96 \%$ depend of the discriminant technic utilized, Avinashi et al. (2019) using vision system for measure tool wear width obtained from the experimentally validated average error of 3\%., Schmitt(2012) analyzed tool wear inspection for flank wear and tool breakage utilized other features from image obtained accuracy $98 \%$ and deviation measure of the $0.0 .1 \mathrm{~mm}$ similar than work.

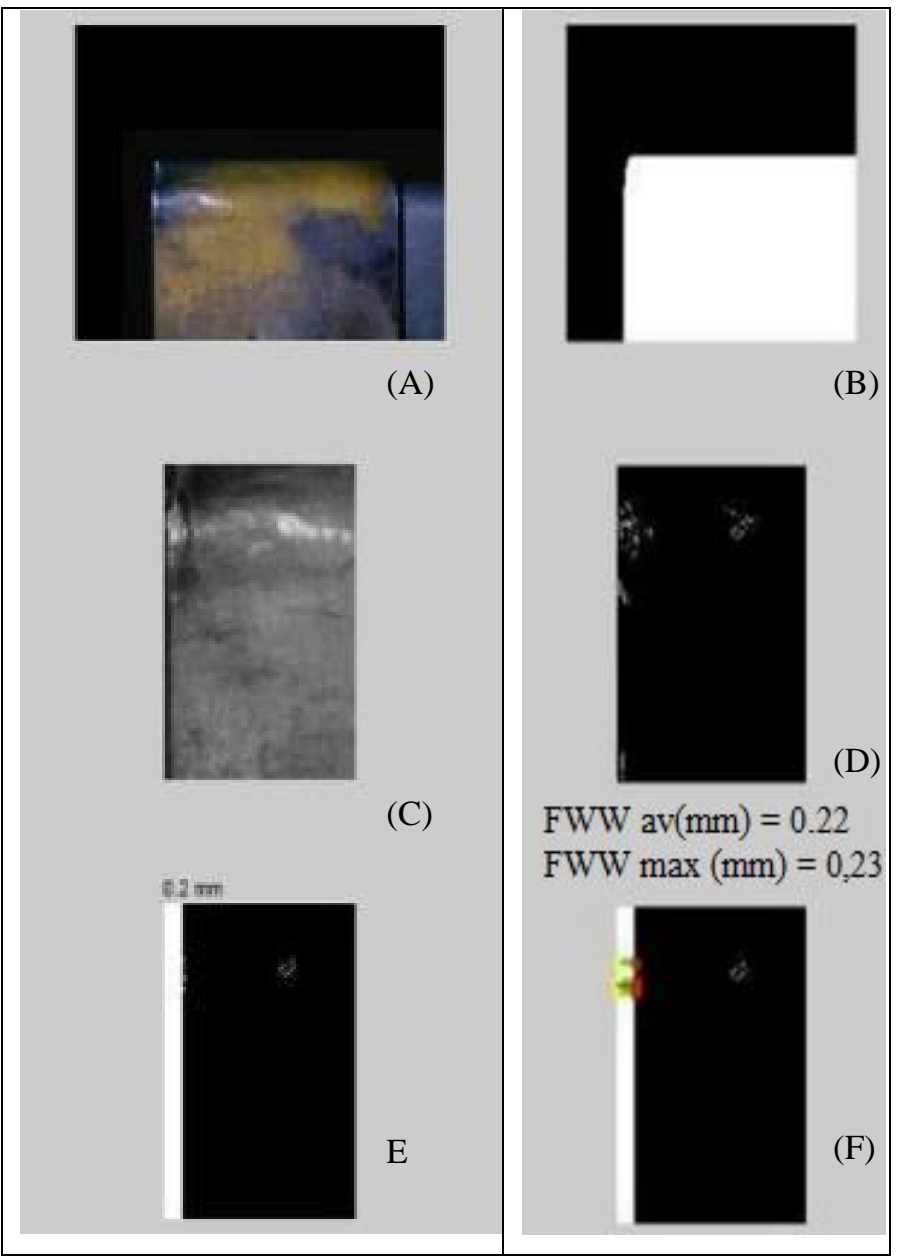

Figure 8- Example image processing of insert: (A) original image, (B) contour of insert, (C) goal image, (D) edge image, $(E)$ removal noises and add bar of $0.2 \mathrm{~mm}$ in top insert, (F) lines found using Hough transform and the FWW (flank wear width) average of $0.22 \mathrm{~mm}$ and maximum of $0.23 \mathrm{~mm}$. 


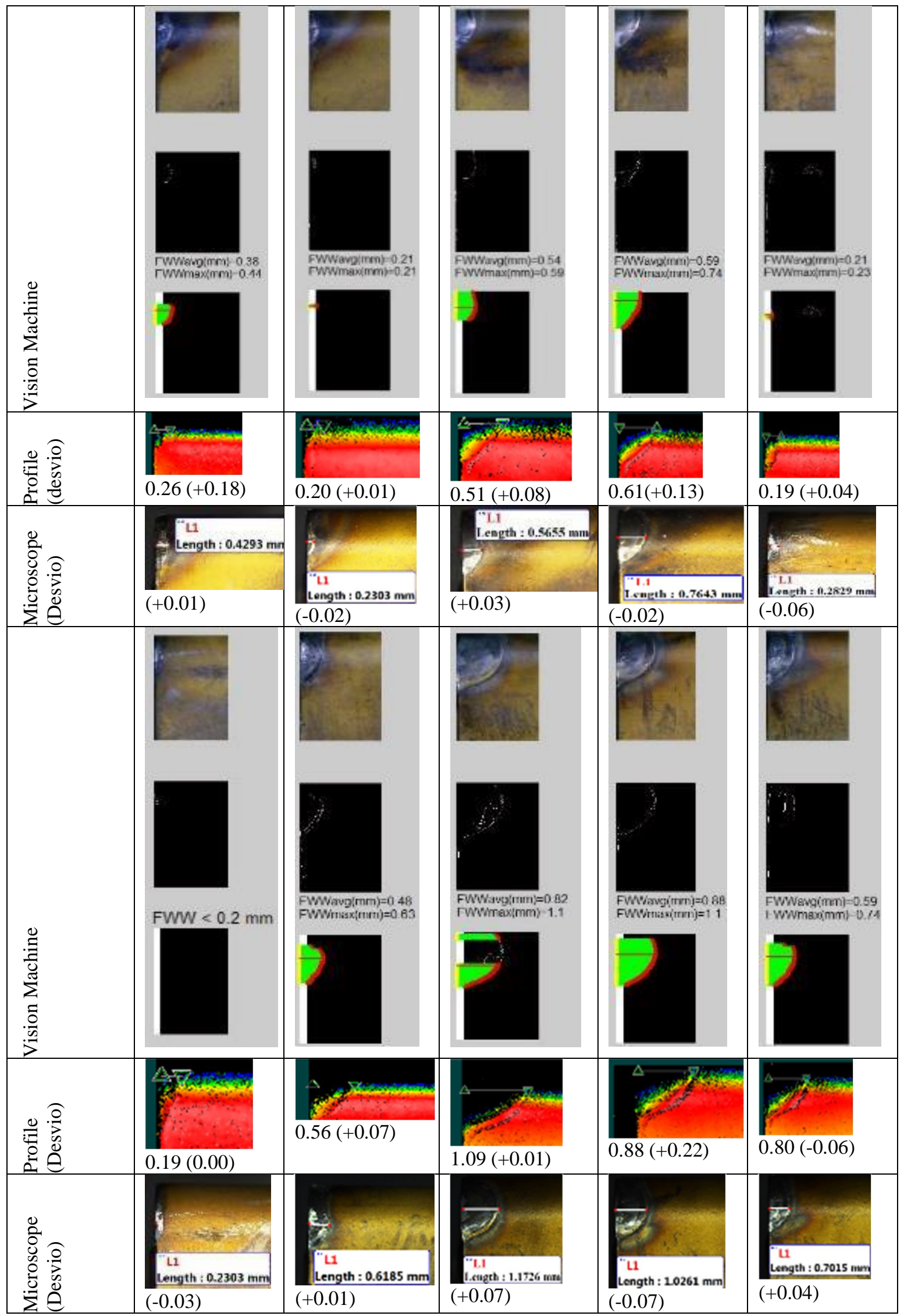

Figure 9 - Deviations of the FWW max between optical microscope, surface profile, and developed machine vision system. 


\section{4 -CONCLUSION}

The work was to develop a system to identify and measure tool wear. Thus, the system has an acceptable accuracy of the $94,3 \%$ to discriminate FWW and breakage. And to measure FWW was just hundredth millimeter, a deviation between Vision System developed with optical microscope and surface profile was average of $0.04 \mathrm{~mm}$, and $0.08 \mathrm{~mm}$, respectively. Showing that image processing techniques as discriminant function and Hough Transform should be used for this

\section{5 - ACKNOWLEDGEMENTS}

The authors thank the Universidade Federal de Viçosa, University of Florida, CAPES and FAPEMIG to supporting this research.

\section{REFERENCES}

AVINASH, A. T.; ANIRUDDHA V. L.; KIRAN M. Measurements of Tool Wear Parameters Using Machine Vision System. Modelling and Simulation in Engineering, vol. 2019, Article ID $1876489, \quad 9$ pages, 2019. https://doi.org/10.1155/2019/1876489.

BHUSHAN, R. K., Multiresponse Optimization of Al Alloy-SiC Composite Machining Parameters for Minimum Tool Wear and Maximum Metal Removal Rate. Journal of Manufacturing Science and Engineering, 135(2), Apr 2013. https://doi.org/10.1115/1.4023454.

CAPASSO, S.; PAIVA, J.M.; LOCKS JUNIOR, E.; SETTINERI, L; YAMAMOTO, K; AMORIM, F.L.; TORRES, R.D.; COVELLI, D.; FOXRABINOVICH, G.; VELDHUIS, S.C. A novel method of assessing and predicting coated cutting tool wear during Inconel DA 718 turning, Wear, v. 432-433, August 2019. https://doi.org/10.1016/j.wear.2019.202949

DA SILVA; M.B. et. al, Analysis of wear of cemented carbide cutting tools during milling operation of gray iron and compacted graphite iron, WEAR, vol. 271, 2426ï 2432, 2011. https://doi.org/10.1016/j.wear.2010.11.030

GONZALEZ, R.C. and Woods, R.E. Digital Image Processing, Prentice Hall, 2008.

ISO 3685, Tool-life testing with single-point turning tools, 1993.

JOHNSON, R. A.; WICHERN, D. W., Applied Multivariate statistical analysis, Pearson Prentice Hall, 2007.
KANG, L.; WANG, S.; WANG; S.; MA, C.; YI, L.; ZOU, $H$. Advances in Mechanical Engineering, $\quad$ v. 11,2019. https://doi.org/10.1177/1687814019849172

KHOURY JUNIOR, J.K.; PINTO, F.A.C., SANTOS; N.T., LÚCIA; R.M.D.; MAEDA, E.E., Análise discriminante paramétrica para reconhecimento de defeitos em tábuas de eucalipto utilizando imagens digitais. Revista Árvore, Viçosa-MG, v.29, n.2, p.299-309, 2005. http://dx.doi.org/10.1590/S010067622005000200013

LIEW, W.Y.H.; DING , X.; Wear progression of carbide tool in low-speed end milling of stainless steel, Wear, V.265, p.155-166, June/2008. http://dx.doi.org/10.1016/j.wear.2007.09.003.

MAINI, R.; AGGARWAL, H. Study and comparison of various image edge detection techniques, International Journal of Image Processing, vol.3, No. 1, Feb. 2009

MANNAN, M.A. et al., Tool wear monitoring using a fast Hough transform of images of machined surfaces, Machine Vision and Applications, vol 15, pag. 156ï 163, 2004.

MatLab userô Guide, The Math Works Inc., 2009.

SAS Institute. SAS Online Doc. Version 9.13, SAS Institute Inc., Cary, USA, 2009.

SCHMITT, R.; CAI, Y.; PAVIM, A. Machine Vision System for Inspecting Flank Wear on Cutting Tools, ACEEE Int. J. on Control System and Instrumentation, vol. 03, No. 01, Feb 2012.

SHI, D.; GINDY, N. N. Tool wear predictive model based on least squares support vector machines, Mechanical Systems and Signal Processing, Volume 21, Issue 4, Pages 1799-1814, May 2007, http://dx.doi.org/10.1016/j.ymssp.2006.07.016.

TLUSTY, G, Manufacturing Processes and Equipment, Prentice-Hall, 2000

XIONG, J.; GUO, Z.; YANG, M.; WAN, W.; DONG, G. Tool life and wear of WCï TiCïCo ultrafine cemented carbide during dry cutting of AISI H13 steel, Ceramics International, V. 39, Issue 1, pag. 337-346, January 2013. https://doi.org/10.1016/j.ceramint.2012.06.031

ZHANG, C. AND ZHANG, J. On-line tool wear measurement for ball-end milling cutter based on machine vision, Computers in Industry, Vol. 64, Issue 6, Pages 708-719, 2013. https://doi.org/10.1016/j.compind.2013.03.010 